\title{
PREVALENCE OF SLEEP DISTURBANCE AMONG NURSES IN A MALAYSIAN GOVERNMENT HOSPITAL AND ITS ASSOCIATION WITH WORK CHARACTERISTICS
}

\author{
Nazatul SM, Saimy I, Moy FM, Nabila AS \\ Department of Social and Preventive Medicine, Faculty of Medicine, University of Malaya, Kuala Lumpur.
}

\begin{abstract}
The objective of this study was to determine the prevalence of sleep disturbance with work characteristics among nurses in the Melaka Hospital, Malacca, Malaysia. This was a cross sectional study conducted in Melaka Hospital. Universal sampling was conducted and a Malay version of the Pittsburgh Sleep Quality Index (PSQI) questionnaire was used in data collection. Sociodemographic characteristics such as age, marital status, number of children and work characteristics such as type of work schedule and duration were also enquired. Factors associated with poor sleep quality were compared between those nurses with good sleep quality by using logistic regression. There were 607 nurses who completed the questionnaire with a response rate of $73.1 \%$. There was a moderate prevalence (57.8\%) of poor sleep quality (PSQI > 5) in all study subjects. The prevalence of sleep disturbance was more widespread among nurses who worked shifts (62.0\%) compared to non-shift working nurses $(41.5 \%) p<0.001$. A logistic regression analysis showed that age, marital status and unit group were the major associating factors of poor sleep quality. Sleep disturbance decreased with increasing age $(\mathrm{OR}=0.42,95 \% \mathrm{Cl} 0.25,0.73)$ while married nurses $(O R=2.3,95 \% \mathrm{Cl} 1.42,3.82)$ and those in the category of intensive group $(\mathrm{OR}=2.1,95 \% \mathrm{Cl} 1.1,4.1)$ were more prone to have sleep disturbances. In conclusion, this study revealed moderate prevalence of sleep disturbance among nurses working in Melaka Hospital but it was not associated with the work shifts. Age, marital status and work environment especially in the intensive group unit seemed to be factors associated with reduced global sleep quality among nurses in this study. (JUMMEC 2008; 11 (2): 66-71)
\end{abstract}

KEYWORDS: sleep disturbance, shift work, nurses

\section{Introduction}

Sleep is a natural periodic state of rest for the mind and body, in which the eyes usually close and consciousness is completely or partially lost, so that there is a decrease in bodily movement and responsiveness to external stimuli (1). The amount of sleep each person needs depends on many factors, including age. Infants generally require about 16 hours a day while teenagers need about nine hours on average and for most adults, seven to eight hours a night is enough although some people may need as few as five hours or as many as ten hours of sleep each day (2). When human beings do not obtain enough sleep, people will think and move slowly and make more mistakes. The consequences of sleep deprivation include susceptibility to common viral illnesses, diabetes, obesity, heart disease, and depression (3).

The causes of sleep disturbance are many and varied.
For a variety of reasons, nurses are particularly prone to sleep disturbance. Nurses face many problems that may negatively affect sleep quality, including work schedule. Within the health care services, the need for 24-hour nursing care requires nurses to work on shift systems. Shift work is used to describe as a variety of working time arrangements, including: (a) working outside daytime hours such as night shifts; (b) overtime work; or (c) irregular or rotational work patterns (a system in which staff are required to work a combination of day, afternoon and night shifts) (4). Nonshift schedule refers to working during the hours which an

Correspondance :

Nazatul Shima Mokhtar

Department of Social and Preventive Medicine

Faculty of Medicine, University of Malaya

50603 Kuala Lumpur

Email:dr_shima@hotmail.com 
office is normally open for business or consultation or in other words, following a standard work day/office hours (8.00 to 5.00 p.m.) or a permanent/fixed time/ hour day.

In a study of sleep disturbance among 817 hospital staff workers, $29.7 \%$ of health staff scheduled for rotating daytime shifts experienced disrupted sleep occurring two nights or more per week. These workers also reported significantly more difficulty in initiating sleep than fixed daytime workers $(20.1 \%$ and $12 \%$, respectively) (5).

A study among nurses in Thailand showed that there was a high prevalence (73\%) of poor sleep quality and the prevalence was more widespread among nurses working in shifts (76.7\%) than nonshift nurses $(p<0.0002)$. That study also showed that poor sleep quality was inversely related to age $(p<0.001)(6)$. Prevalence of insomnia among shift-working nurses (29.2\%) was three to four times higher than that in the general population in a study conducted in Japan (7). Beside shift work, other factors affecting sleep quality are age, marriage, number of children and duration of work predisposed to sleep disturbance (3, $6,8)$. In Malaysia, the prevalence of sleep disturbance among nurses or other factors contributing to sleep disturbance have not been well studied. The objectives of this study were to determine the prevalence of sleep disturbance among nurses in the Melaka Hospital and the association between sleep disturbance and work characteristic of the nurses.

\section{Materials and Methods}

This study was a cross-sectional study conducted in Melaka Hospital in Malaysia. The study population were nurses who worked in the Melaka Hospital. The sampling method was universal and data were collected from June to October 2006. All nurses who worked in Melaka Hospital and fulfilled the inclusion criteria (had worked more than two months in the hospital and was registered with the Ministry of Health, Malaysia) during the data collection period were invited to participate in the study. From 926 nurses, 830 nurses fulfilled the criteria. Out of these, 679 nurses were working on rotational shifts and 151 were on nonshifts. Work units were divided into four categories: Medical, Surgery, Intensive and Ambulatory Groups.
The study instrument used the Malay version of Pittsburgh Sleep Quality Index (PSQI). PSQI was developed by Buysse et al (9) and the source of the questionnaire was cited from The Hartford Institute for Geriatric Nursing, Division of Nursing, New York University. The PSQI is a self-rated questionnaire that is useful in determining whether a person has a significant sleep disturbance over the previous month. Nineteen individual items generate seven component scores: subjective sleep quality, sleep latency, sleep duration, habitual sleep efficiency, sleep disturbance, use of sleep medication and daytime dysfunction. A PSQI total score greater than five is diagnostic of sleep disturbance and differentiates between nurses that have sleep of good quality from those with poor quality sleep. A pre-test was performed among 38 nurses in the Alor Gajah Hospital, Kedah to test and to verify that the questionnaire was easily understood by the respondents. The data were entered into a computer using the SPSS Version 13.0 software. Data were cleaned and checked before analysis. These data were coded appropriately according to the type of variables. Univariate significance between various factors and sleep disturbance were identified using binary logistic regression. Multivariate logistic regression was used to examine the association of various factors with sleep disturbance while simultaneously controlling for potential confounders. The significance of association and its precision was determined by the $95 \%$ confidence interval and the magnitude was determined by the crude odds ratio.

\section{Results}

Out of 830 nurses, 607 (73.1\%) answered the questionnaire. Out of those who responded to the questionnaire, $71.3 \%$ were shift nurses and $80.4 \%$ were nonshift nurses.

Malays formed the largest ethnic group (87.3\%) (Table $1)$. About half of the nurses $(56.2 \%)$ had college/ university education, and most of them were married (85.5\%). $79.7 \%$ of the nurses worked on the shift schedule. About $82 \%$ were staff nurses while $12.5 \%$ were community nurses. Nurses from Surgery were the majority $(44.2 \%)$ followed by the Medical group (37.4\%).

Out of the 607 respondents who answered the questionnaire, our study showed that 351 nurses had 
Table 1: Sociodemographic and Work Characteristics of Respondents

\begin{tabular}{|c|c|}
\hline Characteristics & n (\%) \\
\hline \multicolumn{2}{|l|}{ Ethnicity } \\
\hline Malay & $530(87.3)$ \\
\hline Chinese & $59(9.7)$ \\
\hline Indian & $12(2.0)$ \\
\hline Others & $6(1.0)$ \\
\hline \multicolumn{2}{|l|}{ Marital Status } \\
\hline Single & $81(13.3)$ \\
\hline Married & $519(85.5)$ \\
\hline Widow/Divorced & $7(1.2)$ \\
\hline \multicolumn{2}{|l|}{ Education level } \\
\hline Secondary & $266(43.8)$ \\
\hline College/University & $341(56.2)$ \\
\hline \multicolumn{2}{|l|}{ No of children } \\
\hline 0 & $151(24.9)$ \\
\hline $1-2$ & $254(41.8)$ \\
\hline $3-4$ & $167(27.5)$ \\
\hline$>4$ & $35(5.8)$ \\
\hline \multicolumn{2}{|l|}{ Type of work } \\
\hline Non shift & $123(20.3)$ \\
\hline Shift & $484(79.7)$ \\
\hline \multicolumn{2}{|l|}{ Job rank } \\
\hline Matron/Sister & $21(3.5)$ \\
\hline Staff nurse & $498(82.0)$ \\
\hline Community nurse/Midwife & $76(12.5)$ \\
\hline Assistant nurse & $12(2.0)$ \\
\hline \multicolumn{2}{|l|}{ Unit group } \\
\hline Medical & $227(37.4)$ \\
\hline Surgery & $268(44.2)$ \\
\hline Intensive & $60(9.9)$ \\
\hline Ambulatory & $52(8.6)$ \\
\hline \multicolumn{2}{|l|}{ Job duration } \\
\hline 1 month- 5 years & $265(43.7)$ \\
\hline 6-10 years & $149(24.5)$ \\
\hline $11-15$ years & $51(8.4)$ \\
\hline $16-20$ years & $46(7.6)$ \\
\hline $21-25$ years & $38(6.3)$ \\
\hline$>26$ years & $58(9.6)$ \\
\hline
\end{tabular}

$(n=607)$

sleep disturbance $(57.8 \%)$ (Table 2 ). The prevalence of sleep disturbance was significantly highest among Malay nurses $(p=0.021)$. Age was inversely related to sleep disturbance $(p=0.002)$ where nurses aged 50 to 59 years old has the least sleep disturbance with the lowest $95 \% \mathrm{Cl}(\mathrm{OR}=0.41(0.24,0.67)$ compared to young nurses. Married nurses were more prone to have sleep disturbances (OR $1.9895 \% \mathrm{Cl} 1.23,3.18$ )
Table 2: Association between Sleep Disturbance and Socio Demographic Characteristics among Respondents

\begin{tabular}{|c|c|c|c|c|}
\hline Characteristics & $\begin{array}{c}\text { No Sleep } \\
\text { Disturbance } \\
(\mathbf{n}=256) \\
n(\%)\end{array}$ & $\begin{array}{c}\text { Sleep } \\
\begin{array}{c}\text { Disturbance } \\
(n=351)\end{array} \\
n(\%)\end{array}$ & OR 95\% CI & $\begin{array}{c}\mathbf{p} \\
\text { value* }\end{array}$ \\
\hline Ethnicity & & & & 0.021 \\
\hline Malay & 211 (39.8) & $319(60.2)$ & $0.45(0.26,0.78)$ & \\
\hline Chinese & $35(59.3)$ & $24(40.7)$ & $0.66(0.21,2.08)$ & \\
\hline Indian & $6(50.0)$ & $6(50)$ & $0.33(0.06,1.82)$ & \\
\hline Others & $4(66.7)$ & $3(33.3)$ & & \\
\hline Age & & & & 0.002 \\
\hline $20-29$ & $91(38.7)$ & $144(61.3)$ & $1.09(0.72,1.64)$ & \\
\hline $30-39$ & $62(36.7)$ & $107(63.3)$ & $0.83(0.53,1.31)$ & \\
\hline $40-49$ & $50(43.1)$ & $66(56.9)$ & $0.41(0.24,0.67)$ & \\
\hline $50-59$ & $53(60.9)$ & $34(39.1)$ & & \\
\hline Marital Status & & & & 0.018 \\
\hline Single & $46(56.8)$ & $35(43.2)$ & $1.98(1.23,3.18)$ & \\
\hline Married & 207 (39.9) & $312(60.1)$ & $1.75(0.37,8.34)$ & \\
\hline Widow/Divorce & $3(42.9)$ & $4(57.1)$ & & \\
\hline BMI & & & & 0.406 \\
\hline Under weight & $11(30.6)$ & $25(69.4)$ & $0.55(0.27,1.15)$ & \\
\hline Normal & $149(44.5)$ & $186(55.5)$ & $0.65(0.30,1.40)$ & \\
\hline Over weight & $72(40.4)$ & $106(59.6)$ & $0.62(0.26,1.50)$ & \\
\hline Obese & $24(41.4)$ & $34(58.6)$ & & \\
\hline Education Level & & & & 0.104 \\
\hline $\begin{array}{l}\text { Secondary } \\
\text { School }\end{array}$ & $122(45.9)$ & $144(54.1)$ & $1.31(0.95,1.81)$ & \\
\hline $\begin{array}{l}\text { College/ } \\
\text { University }\end{array}$ & $134(39.3)$ & $207(60.7)$ & & \\
\hline No. of children & & & & 0.176 \\
\hline 0 & $74(49.0)$ & $77(51.0)$ & $1.56(1.03,2.34)$ & \\
\hline $1-2$ & $97(38.2)$ & $157(61.80)$ & $1.27(0.81,1.98)$ & \\
\hline $3-4$ & $72(43.1)$ & 95 (56.9) & $1.63(0.76,3.47)$ & \\
\hline$>4$ & $13(37.1)$ & $22(62.9)$ & & \\
\hline $\begin{array}{l}\text { No.of } \\
\text { dependent }\end{array}$ & $47(48.5)$ & $50(51.5)$ & $1.13(0.71,1.79)$ & 0.0927 \\
\hline 0 & $138(45.5)$ & $166(54.6)$ & $1.74(1.05,2.89)$ & \\
\hline $1-2$ & $60(35.1)$ & $111(64.9)$ & $2.07(0.89,4.82)$ & \\
\hline $3-4$ & 1031.3) & $22(68.8)$ & $1.88(0.17,21.4)$ & \\
\hline $5-6$ & $1(33.3)$ & $2(66.7)$ & & \\
\hline$>6$ & & & & \\
\hline
\end{tabular}

compared to single nurses. BMI, education level, number of children and number of dependants were not significant factors in this study.

Shift nurses had 2.3 times higher risk of haing sleep disturbance with OR $2.30(95 \% \mathrm{Cl} 1.54,3.44)$ compared to nonshift nurses (Table 3). The unit group was significant in this study $(<0.001)$. The crude OR for 
Table 3: Association between Sleep Disturbance and Work Characteristics among Respondents

\begin{tabular}{|c|c|c|c|c|}
\hline Characteristics & $\begin{array}{l}\text { No Sleep Disturbance ( } \mathrm{n}=\mathbf{2 5 6}) \\
\mathrm{n}(\%)\end{array}$ & Sleep Disturbance ( $n=351)$ n (\%) & $95 \% \mathrm{Cl}$ & p value* \\
\hline Type of work & & & & 0.0001 \\
\hline Nonshift & $72(58.5)$ & $51(41.5)$ & \multirow[t]{2}{*}{$2.30(1.54,3.44)$} & \\
\hline Shift & $184(38.0)$ & $300(62.0)$ & & \\
\hline Job rank & & & \multirow{5}{*}{$\begin{array}{l}1.99(0.82,4.80) \\
1.33(0.50,3.53) \\
1.33(0.32,5.54)\end{array}$} & 0.180 \\
\hline Matron/Sister & $12(57.1)$ & $19(42.9)$ & & \\
\hline Staff Nurse & 20040.2) & $298(59.8)$ & & \\
\hline Com Nurse & $38(50.0)$ & $38(50.0)$ & & \\
\hline Assistant Nurse & $6(50.0)$ & $6(50.0)$ & & \\
\hline Unit group & & & \multirow{5}{*}{$\begin{array}{l}0.81(0.64,1.320 \\
1.97(1.16,4.30) \\
0.32(0.16,0.58)\end{array}$} & 0.0001 \\
\hline Medical & \multirow{4}{*}{$\begin{array}{c}92(40.5) \\
114(42.5) \\
14(23.3) \\
36(69.2)\end{array}$} & \multirow{4}{*}{$\begin{array}{c}135(59.5) \\
154(57.5) \\
46(76.6) \\
16(30.8)\end{array}$} & & \\
\hline Surgery & & & & \\
\hline Intensive & & & & \\
\hline Ambulatory & & & & \\
\hline Job duration & & & & 0.011 \\
\hline $0-5 \mathrm{yrs}$ & $110(41.5)$ & $155(58.5)$ & $1.29(0.85,1.95)$ & \\
\hline $6-10$ years & $53(35.6)$ & $96(64.4)$ & $1.20(0.64,2.22)$ & \\
\hline $11-15$ years & $19(37.3)$ & $32(62.7)$ & $1.21(0.63,2.31)$ & \\
\hline $16-20$ years & $17(37)$ & $29(63.0)$ & $0.46(0.23,0.93)$ & \\
\hline $21-25$ years & $23(60.5)$ & $15(39.5)$ & $0.50(0.28,0.89)$ & \\
\hline$>26$ years & $34(58.6)$ & $24(41.4)$ & & \\
\hline
\end{tabular}

${ }^{*} \chi 2$ test

nurses who worked in the Intensive group was highest $(\mathrm{OR}=2.24,95 \% \mathrm{Cl} 1.16,4.30)$ while the Ambulatory group was noted to have the least sleep disturbance $(\mathrm{OR}=0.32,95 \% \mathrm{Cl} 0.16,0.58)$. Job duration was significantly associated with sleep disturbance $(p=0.011)$ while the job rank was not significant.

Table 4 shows the multiple logistic regression analyses performed on all significant predictors that had meaningful association on the outcome on sleep disturbance. The findings showed that the factors associated with sleep disturbance were marital status, age and unit group. Age between 50 to 59 years had least sleep disturbance compared to other age groups. Married nurses was twice more common to obtain sleep disturbance compared to single nurses. Similar to those nurses who worked in the Intensive Group, they were twice more prone to experience sleep disturbance as compared to other unit groups.
Table 4: Predictors of sleep disturbance among respondents

\begin{tabular}{lccc}
\hline Characteristics & Crude OR & Adjusted OR & $\mathbf{9 5 \%} \mathbf{C l}$ \\
\hline Marital status & & & \\
Single & 1.00 & 1.00 & $1.42,3.82$ \\
Married & 1.98 & 2.33 & $0.56,14.55$ \\
Widow/Dvorced & 1.75 & 2.87 & \\
\hline Age group & & & \\
$20-29$ & 1.00 & 1.00 & $0.65,1.51$ \\
$30-39$ & 1.09 & 0.99 & $0.51,1.34$ \\
$40-49$ & 0.83 & 0.83 & $0.25,0.73$ \\
50 - 59 & 0.41 & 0.42 & \\
\hline Unit group & & & \\
Medical & 1.00 & 1.00 & $0.64,1.34$ \\
Surgery & 0.81 & 0.93 & $1.08,4.10$ \\
Intensive & 1.97 & 2.11 & $0.19,0.75$ \\
Ambulatory & 0.32 & 0.38 &
\end{tabular}




\section{Discussion}

More than half of the nurses in this study had sleep disturbance during the month before completing the questionnaire and met the PSQI criteria for "poorer sleep." The percentage of nurses in the current study who scored global sum of PSQI more than 5 points (considered to have sleep disturbance) was $57.8 \%$ and the prevalence was higher for shift nurses compared to nonshift nurses. Most studies showed a lower prevalence of sleep disturbance than this study. However, there are studies that showed a prevalence of sleep disturbance of more than fifty percent $(6,8)$. After the statistical adjustments, the current study did not find a significant effect of work schedule on sleep quality. Similar findings were found elsewhere $(10,11)$.

In this study, marital status was strongly associated with sleep disturbance where married nurses were twice more likely to develop sleep disturbance. A study among 128 nurses had shown that higher prevalence of sleep disturbance was found among married nurses (97.54\%) compared to single nurses (83.33\%) (8). It was noted in the current study that most married nurses had children. Family and domestic work would lead to fatigue or stress that affected sleep quality $(12,13)$. A few studies had shown that being married and having children lead to less sleep and less time for free-time activities $(14,15)$.

Age showed significant association with sleep disturbance in this study. Age between 50 to 59 years had the least sleep disturbance compared to other age group. This study is similar to other studies where age is inversely related to sleep disturbance $(6,16)$. In our current study, nurses in the Intensive group showed a higher prevalence of sleep disturbance compared to other group units. Similar to findings from Ruggiero et al, nurses who work in intensive or critical care units such as ICU, CCU, burns unit and high dependency ward have higher prevalence of sleep disturbance $(6,17)$.

\section{Conclusion}

In conclusion, our findings showed that working on shift work schedule did not always lead to the presence of sleep disturbance. Other factors that predisposed nurses to develop sleep disturbance were age, marital status and work environment. Work related characteristic such as work load may lead them to develop sleep disturbance or sleep deprivation as well. In light of the present findings, there is a need to do more research and further investigation to determine other factors that may be related to sleep disturbances among nurses.

\section{References}

1. Houghton M. The American Heritage Medical Dictionary. Boston: Houghton Mifflin Company; 2004.

2. Carpenito Moyet LJ. Handbook of Nursing Diagnosis. 11th ed. Philadelphia: Lippincott William \& Wilkins; 2006.

3. Learthart S. Health effects of internal rotation of shifts. Nurs Std, 2000; 14 (47): 34-36.

4. Efinger J. Nelson LC. Starr JM. Understanding circadian rhythms: a holistic approach to nurses and shift work. J Holistic Nurs 1995; 13:306-322.

5. Ohayon MM., Lemoine P, Arnaud-Briant V, Dreyfus $M$. Prevalence and consequences of sleep disorders in a shift worker population. J Psychosomatic Res July 2002; 53 (1):577-583.

6. Tawanchai J, Waran T. Sleep disturbance among nurses of Songklanagaring Hospital. J Psychiatr Assoc Thailand. 1997; 42, (3):123-132.

7. Kageyama T, Nishikido T, Oga J, Kawashima M. Cross sectional survey on risk factors for insomnia in Japanese female hospital nurses working rapidly rotating shift systems. J Hum Ergol (Tokyo). 2001; 30 (1-2):149-54.

8. Almasi H, Saberi H, M. Motallebi HM. Prevalence of sleep disorder in nurses working on rotating shifts. J Appl Sci 2006; 6 (3):644-646.

9. Buysse, DJ, Reynolds III CF, Monk, TH, et al. The Pittsburgh Sleep Quality Index: A new instrument for psychiatric practice and research. J Psychiatr Res, 1989; 28 (2):193-213.

10. Ohida T, Kamal AAM, Tomofumi S, et al. Night-shift work related problems in young female nurses in Japan. J Occup Health. 2001;43:150-156.

11. Takahashi M, Fukuda M, Miki K, et al. Shift workrelated problems in 16 -h night shift nurses (2): effects on subjectives symptoms, physical activity, heart rate and sleep. Ind Health 1999; 37: 228-236. 
12. Samaha E, Lal S, Samaha N, Wyndham J. Psychological, lifestyle and coping contributors to chronic fatigue in shift-worker nurses. $J$ Adv Nur 2007; 59 (3): 221-232.

13. Kunert K, King M, Kolkhorst F. Fatigue and sleep quality in nurses. J Psychoso Nurs Ment Health Serv Aug 2007; 45 (8):31-37.

14. Ohida T, Takemura S, Nozaki N, et al. The influence of lifestyle and night-shift work on sleep problems among female hospital nurses in Japan. Nippon Koshu Eisei Zasshi 2001; 48:595-603.
15. Kurumatani N, Koda S, Nakagiri S, et al. The effects of frequently rotating shiftwork on sleep and the family life of hospital nurses. Ergonomic, 1994;37 (6):995-1007.

16. Suzuki K, Ohida T, Kaneita Y, et al. Daytime sleepiness, sleep habits and occupational accidents among hospital nurses. J Adv Nurs 2005; 52 (4): 445-453.

17. Ruggiero JS. Correlates of fatigue in critical care nurses. Res Nurs Health 2003; 26: 434-444. 